\title{
Boas e más razões para cooperar do ponto de vista de crianças - uma análise evolucionista
}

\author{
Anuska Irene Alencar \\ Faculdade de Ciências, Cultura e Extensão do Rio Grande do Norte \\ Secretaria Municipal de Saúde de Natal/RN
}

\begin{abstract}
Resumo
A cooperação é um comportamento aparentemente oposto à seleção natural, no entanto, é também compatível se a entendermos como um mecanismo pelo qual os indivíduos podem aumentar a aptidão. Esse comportamento tem sido investigado pelos psicólogos evolucionistas que identificam algumas razões para sua existência - como a seleção de parentesco, o altruísmo recíproco e o altruísmo recíproco indireto. Poucos estudos evolucionistas são realizados em crianças. Nesse sentido, o objetivo deste trabalho foi analisar relatos que corroboram com achados evolucionistas identificados em adultos. Foi observado que, nos relatos, podemos identificar exemplos de seleção de parentesco, altruísmo recíproco, altruísmo recíproco indireto, bem como a importância da reputação para desencadear comportamentos de cooperação dos parceiros do jogo.
\end{abstract}

Palavras-chave: trapaceiros; cooperação; teoria dos jogos.

\begin{abstract}
Good and bad reasons to cooperate from the viewpoint of children - an evolutionary analysis. Cooperation is a behavior apparently opposed to natural selection, however it is possible of comparation if we understand as a mechanism by which individuals can increase aptitude. This behavior has been investigated by the evolutionist psychologists whom identify some reasons for its existence such as the kinship election, the reciprocal altruism and the indirect reciprocal altruism. Very little evolutionist studies have been developed with children. Thus, the objective of this work was to analyze reports which corroborate with evolutionist findings, identified in adults. It was observed that, in the reports, one can identify examples of the kinship election, the reciprocal altruism and the indirect reciprocal altruism, as well as the importance of reputation to trigger cooperative behavior of the game partners.
\end{abstract}

Keywords: free riders; cooperation; games theory.

A cooperação é aparentemente oposta à seleção natural, tendo em vista que o fundamento básico da teoria da evolução é a competição, e que o ato de cooperar implica custos para o executor (como gasto de energia, por exemplo) e benefícios gerados para quem recebe a ajuda. Nesse sentido, poderíamos esperar que a seleção natural mantivesse os comportamentos que trouxessem benefícios maiores do que seus custos, o que não parece ser o caso da cooperação. A literatura da área aponta algumas possibilidades nas quais a cooperação favorece a aptidão do indivíduo como: seleção de parentesco, altruísmo recíproco e altruísmo recíproco indireto. A Psicologia Evolucionista propõe que a cooperação tenha tido um papel importante para os indivíduos no ambiente ancestral ou Ambiente de Adaptação Evolutiva (AAE).

Esse ambiente é definido como um conjunto de pressões seletivas enfrentadas pelos ancestrais de um organismo durante um tempo evolutivo. Os indivíduos selecionados naquele ambiente teriam uma estrutura organizada de modo a serem bem sucedidos naquelas condições ambientais do passado evolutivo (Izar, 2009), e a cooperação parece ter sido importante no AAE, em função das condições em que viviam os seres humanos aproximadamente há dez mil gerações.

As sociedades humanas, no AAE, provavelmente evoluíram a partir de grupos com fortes laços de parentesco, o que seria a forma mais elementar de sociedade humana, como propõem Johnson e Earle (2000). Um grupo típico desse nível teria em torno de 25 indivíduos que se dividiam em outros pequenos grupos, comiam juntos, cooperavam e partilhavam alimentos e outros itens. Os laços sociais eram mantidos com base na confiança. As competições existiriam em caso de extrema escassez de recursos. Embora, como regra, não houvesse privilégios para alguns membros da família, nem a ocorrência de trapaceiros (indivíduos que não cooperam, mas usufruem da cooperação do outro) no ambiente familiar, estar em grupo era vantajoso e seguro. O número pequeno de indivíduos facilitava a fiscalização do comportamento de cada um. Desse modo, 
podemos pensar que viver em um grupo, com fortes laços de parentesco, trouxe algumas vantagens para os indivíduos que assim viviam. As vantagens de viver em grupo, e as explicações para a cooperação, não são exclusivas dos indivíduos humanos, mas podem ser extensivas a outras espécies sociais (Alcock, 1989).

A teoria evolucionista considera, como uma forte justificativa para a manutenção do comportamento cooperativo, a seleção de parentesco. Esse seria um mecanismo por meio do qual um indivíduo favorece seus parentes genéticos, considerando que as características dos indivíduos reprodutores são passadas adiante. Essa transmissão pode se dar de forma direta, quando o investimento é na própria prole, ou indireta, quando o indivíduo não reproduz, mas investe na sobrevivência e/ou reprodução da prole dos pais, irmãos, primos e outros parentes. O investimento, nesse caso, pode ser procurar e partilhar comida, carregar os infantes e proteger-se de predadores e de indivíduos que não são do grupo, bem como apresentar outros comportamentos que aumentem as chances de sobrevivência e reprodução dos parentes.

Quando não há relação de parentesco, mas há possibilidade de reencontros entre os indivíduos, ainda é vantajoso cooperar, como sugere Trivers (1971). Ele denominou de altruísmo recíproco esse comportamento, que se pode encontrar inclusive em não humanos, e que se dá por meio de um benefício futuro, dado pelo indivíduo que recebeu o benefício no presente, como no ditado: eu coço as suas costas se você coçar as minhas.

Trivers (1971) demonstra a viabilidade de esse comportamento ter sido selecionado, seguindo os mesmos parâmetros da seleção de parentesco: tempo de vida longo, baixo padrão de dispersão, dependência mútua, estabilidade, vida em grupo. Essas características humanas poderiam levar à necessidade de reciprocidade entre os indivíduos, independente do parentesco.

Essa estratégia explica por que cooperamos ou não em caso de interações repetidas com possibilidade de reencontro, no entanto não explica, quando, em muitas ocasiões, na vida moderna, fazemos doações mesmo não sabendo quem as receberá diretamente. Por exemplo, quando doamos sangue ou fazemos doações a instituições de caridade. Nesse caso, a reciprocidade seria ainda mais incerta. $\mathrm{E}$, ainda assim, por que cooperamos?

Uma possível explicação diz respeito à reputação adquirida ao cooperar ou deixar de fazê-lo. Estudos experimentais mostram que, ao adquirir a reputação de bom doador, um indivíduo atrai cooperação, mesmo que não seja conhecido pelos outros membros do grupo que recebe a doação (Nowak \& Sigmund, 1998; Ohtsuki, Hauert, Liberman, \& Nowak, 2006; Suzuki \& Akiyama, 2005). Esses autores sugerem que temos a tendência a cooperar com quem tem a fama de bom cooperador, mesmo que nunca tenhamos estabelecido uma relação direta com ele. Nesse caso, a cooperação seria estimulada por meio de um mecanismo denominado de altruísmo recíproco indireto.

Grande parte dos achados evolucionistas sobre cooperação utilizou a teoria dos jogos como metodologia de investigação. De acordo com Marinho (2005), há uma semelhança entre as teorias, no sentido em que os indivíduos tentam, em ambas, maximizar seus ganhos e minimizar suas perdas. Dessa forma, os indivíduos com maiores ganhos seriam os mais aptos. Além disso, a possibilidade de tratar de forma matemática os conflitos da relação de cooperação, como, por exemplo, cooperar ou não, facilita a análise dos dados (Alencar \& Yamamoto, 2008).

Os achados mencionados acima utilizaram a teoria dos jogos a partir de estudos teóricos ou experimentais em adultos, mas como seria esse comportamento entre crianças? Estudos sobre a cooperação, altruísmo e comportamento pró-social são controversos. Parte deles refere-se ao julgamento moral e foram realizados por autores, como Piaget e Kohlberg, que tinham uma visão particular do desenvolvimento cognitivo e do julgamento racional (Haidt, 2001; 2003). Em seus estudos eles apontam que as crianças são egoístas até determinada idade (Eisenberg \& Mussen, 1995; Kohlberg, 1984; Piaget, 1932/1994).

O desenvolvimento dessa capacidade pode ser ampliado pelas vivências e ainda pelo ingresso no mundo cheio de regras as quais os adultos propõem. Os teóricos como Kohlberg (1984) e Piaget (1932/1994) assinalam a capacidade da criança em fazer julgamento moral através de estágios que acompanhariam o desenvolvimento cognitivo do indivíduo. Para ambos, a sequência de estágios é a mesma em todas as culturas, ponto que converge com a teoria evolucionista. De acordo com Krebs (2000), os trabalhos de Kohlberg retratam o altruísmo recíproco direto quando se refere ao estágio dois, no qual o indivíduo pensa: faça pelos outros o que você gostaria que fizessem com você. $\mathrm{O}$ estágio três também estaria relacionado à cooperação, mas a pessoa se comportaria de modo a receber aprovação pelo seu ato - fato que parece estar de acordo com os resultados em adultos sobre as retribuições serem maiores para sujeitos que cooperam (Milinski, Semmann, \& Krambeck, 2002; Nowak \& Sigmund, 1998).

Trabalhos com uma compreensão evolucionista como o de Benenson, Pascoe e Radmore (2007) apontam que, a partir dos quatro anos e através de ações simples e imitativas, as crianças podem apresentar comportamentos mais complexos e altruístas. Um estudo sobre o desenvolvimento da capacidade de cooperar com um colega foi realizado por Brownell, Ramani e Zerwas (2006), que verificaram que a cooperação pode aparecer cedo, aos dois ou três anos.

A influência da idade também foi observada no estudo citado em Zarbatany, Hartmann e Gelfand (1985). Eles observaram que crianças de 10 anos, cuja faixa etária variava entre seis e 10 anos, apresentam maior grau de generosidade (doação a crianças pobres). No entanto, essa generosidade é evidenciada quando estão em condições de exposição, ou seja: (a) quando os pesquisadores explicam o objetivo da pesquisa e informam às crianças que irão observá-las diretamente, quando fizerem suas opções; (b) quando, além da enunciação das instruções anteriores, afirmam que fazer doações às crianças pobres é bom. Sugere-se, assim, uma relação com o estágio três de Kohlberg (Krebs, 2000).

É importante ressaltar que essas reações não são necessariamente pensadas e calculadas em termos de custos e benefícios das ações. Durante o passado evolutivo, o cérebro usava informações derivadas do ambiente e do próprio organismo a fim de regular funcionalmente o comportamento e o próprio 
corpo, reunindo aspectos cognitivos e emocionais, aspectos enfatizados por autores como Haidt $(2001,2003)$ quando se referem a julgamento moral. No entanto, se os pesquisadores dão informações sobre cooperação ser algo bom, isto influencia a resposta da criança (Fan, 2000; Zarbatany et al., 1985).

Fan (2000) apresentou às crianças uma situação semelhante à do dilema do prisioneiro, um jogo com dois jogadores, e verificou que elas, em sua maioria, cooperavam. Crianças mais velhas (sete a nove anos) tendiam a cooperar mais do que crianças mais novas. Ele verificou, ainda, que a tendência à reciprocidade é maior nas crianças de seis anos de idade do que nas mais novas.

O aprendizado também pode dar-se no outro sentido, ou seja, aprender a ser trapaceiro. Krause e Harbaugh (2000) verificaram que crianças acima de oito anos, em grupos de até cinco indivíduos, também aprendem a se comportar como trapaceiros, nos jogos de bens públicos com várias repetições. Nas últimas sessões, o número de trapaceiros aumentou principalmente entre crianças acima de oito anos. Os autores sugerem que as mais novas não percebem os ganhos de não cooperar com algo e ganhar alguma coisa, como pode acontecer nesse tipo de jogo. Alencar, Siqueira e Yamamoto (2008) encontram resultados semelhantes, no entanto, observaram que a tendência ao aumento do trapaceiro é maior em grupos com mais de 12 indivíduos do que em grupos com menos de sete crianças.

O parentesco, tal qual nos adultos, também influencia as crianças na hora de tomar decisões sobre a partilha. Markovits, Benenson e Kramer (2003) verificaram que as crianças tendem a partilhar alimentos com seus irmãos, independente de sua relação de amizade com eles. O mesmo não ocorre quando eles são questionados se partilhariam alimentos com um colega de sala, com quem eles não mantêm uma boa relação, ou com estranhos. Nesses casos, as crianças até partilham com os colegas de sala se o item em questão não se refere a algo energeticamente importante, ou seja, algo de alto valor para a sobrevivência. Assim, tais resultados indicam que o parentesco é um fator importante na hora de partilhar algo que pode ser útil.

Embora os achados mencionados acima contribuam para a compreensão da permanência da cooperação no repertório comportamental humano, uma análise do que as crianças dizem sobre suas ações durante as coletas pode enriquecer as discussões. Em função disso, o objetivo deste artigo é relatar particularidades dos atos cooperativos e de trapaças revelados durante a coleta de dados dos trabalhos de Alencar (2008), que corroboram com achados evolucionistas identificados em adultos como: seleção de parentesco, altruísmo recíproco, altruísmo recíproco indireto e a importância da reputação para desencadear comportamentos de cooperação dos parceiros do jogo, de modo a ampliar as discussões sobre o tema.

\section{Material e método}

Foram analisados 10 casos de crianças (quatro meninas e seis meninos) e um grupo que participaram dos estudos de Alencar (2008). Os casos relatados referem-se a registros não padronizados de observações que ocorreram durante a coleta de dados. Os comportamentos e relatos das crianças foram anotados pela relevância informativa e evidência da relação com achados evolucionistas para compreensão da cooperação em humanos.

Nos casos em que era possível identificar as doações individuais, como nos experimentos de bens públicos, verificouse nos registros o quanto a criança doou e seu ganho individual foi comparado com o ganho médio do grupo. Quando não nos foi possível identificar as doações individuais, nos casos da Tragédia dos comuns, realizou-se a média de cooperação e trapaça do grupo do qual a criança participou.

Todos os sujeitos tinham, no mínimo, dois meses de convivência na sala de aula. A participação na pesquisa estava condicionada ao conhecimento dos pais sobre sua realização e sua assinatura em um termo de livre consentimento esclarecido, por meio do qual autorizavam a participação dos seus filhos. Para apresentação dos casos, os nomes dos sujeitos foram alterados para manter a privacidade das crianças.

Para o jogo dos bens comuns, as crianças foram divididas em grupos de 7 a 24 indivíduos que recebiam três wafers e eram instruídos a contribuir ou não para um bem comum. Esse bem comum seria depois dividido por igual para todas as crianças. As contribuições poderiam ser de um, dois, três wafers, ou elas poderiam não contribuir, guardando o wafer (reter). As doações eram feitas atrás de um biombo, de maneira a manter o anonimato de quem doou; colocadas em um envelope, que era depois depositado dentro de uma urna. Após todas as crianças fazerem as contribuições, as pesquisadoras adicionavam mais dois wafers a cada um que estivesse no envelope (chamado de retorno) e o total era dividido por igual para todos os membros do grupo, independente das doações individuais. Os wafers não doados não eram recolhidos, portanto, uma vez que todos iniciavam com três, cada indivíduo podia terminar com um total de wafers que era diferente do de outros indivíduos, pois somavam o que os pesquisadores tinham dado ao grupo (retorno) com os que tinham guardado (retorno privado - wafers retidos e não doados).

No experimento da Tragédia dos comuns as crianças eram divididas em grupos de cinco a 18 indivíduos. Para cada participante, foram colocados três wafers em um depósito que ficava atrás de um biombo e as crianças eram instruídas a retirarem wafers do depósito caso fossem sorteadas. Todos iam ao biombo, duas vezes por sessão e, caso fossem sorteados, poderiam pegar dois wafers. O sorteio era manipulado para que cada criança fosse sorteada em uma das idas ao biombo, entretanto, as crianças não tinham essa informação e, como não eram observadas, elas poderiam pegar mais do que dois nas duas idas ao local. Para cada item que sobrasse no recipiente, as pesquisadoras acrescentavam mais dois wafers, caso não sobrasse, o jogo terminava. Nesse jogo, não era possível identificar se a criança tinha cooperado (só pegar dois wafers, se sorteado) ou trapaceado (pegar mais do que dois ou apenas pegar, se não fosse sorteado), mas era calculada a média de cooperação e trapaça e o fim do recurso do grupo do qual ela fazia parte (para mais detalhes sobre a metodologia, ver Alencar, 2008).

Nos dois tipos de experimento, foi solicitado à criança que não revelasse o quanto tinha doado e quanto havia ganhado, no entanto, nem sempre ela seguia essa regra.

\section{Resultados e discussão}


A seleção de parentesco é uma das explicações da teoria da evolução para que o comportamento cooperativo se mantenha. Será que esta força estava presente no comportamento de uma das participantes cognominada de Manuela ( 8,8 anos)? Ou estaria a reputação, outra explicação evolucionista, agindo como causa próxima para desencadear seu comportamento?

No ato do convite, as pesquisadoras informavam que crianças com alergia a chocolates não poderiam participar da brincadeira para evitar que adoecessem (o wafer utilizado nos jogos contém chocolate). Manuela identificou-se como alérgica a chocolate. No dia de receber os termos de livre consentimento esclarecido, o dela estava assinado. Quando questionada sobre ser alérgica, respondeu iria jogar porque a irmã dela não o era e que daria a sua irmã os wafers que ganhasse.

A mãe de Manuela foi consultada sobre a possibilidade da participação dela e, posteriormente, sobre o número de chocolates que Manuela levara para a irmã. A resposta foi aproximadamente compatível com o que havíamos distribuído, exceto pela falta de um número de chocolates que Manuela tinha dado à professora - fato que não verificamos.

Para compreender a cooperação, utilizando a teoria dos jogos e a seleção natural, podemos avaliar os custos e benefícios de Manuela ao fazer a doação para o grupo, doar o total que recebeu para a irmã e para a professora. Tal como proposto por Axelrod e Hamilton (1981), a cooperação só existirá caso os benefícios superem os custos. Essa é uma regra conhecida como regra de Hamilton, expressa na equação: $r b>c$, onde: $r=$ coeficiente de parentesco entre os indivíduos envolvidos na cooperação; $b=$ benefício para o recipiente; $c=$ custo para o doador.

De fato, Manuela não tinha custo algum em doar seus chocolates, estava no momento da aula, não era excluída da turma e ainda era considerada generosa pela família e professora. No entanto, ela não se arriscou tanto. Apesar de um custo baixo para participar do jogo, pois os wafers eram fornecidos pelas pesquisadoras, ela precisava de uma quantidade suficiente para partilhar o ganho com a irmã e a professora.

Observou-se que as doações de Manuela eram sempre um meio termo (ou dois ou um) e ela nunca chegou a doar três wafers. Dessa forma, ela garantia que sua irmã e a professora ganhariam chocolates quando doava ao grupo e guardava para um para a irmã e um para a professora. $\mathrm{O}$ retorno que as pesquisadoras davam era lucro para ela agradar a outras duas pessoas. $\mathrm{Na}$ média das oito sessões, ela ganhou quatro wafers - a média do grupo era de 4,2. Não foi verificado sistematicamente quanto a professora recebeu dela, no entanto, foi registrado pelo menos um a cada dia de coleta, em função de sua proximidade em direção à professora.

Essa criança teve um ganho secundário, fazendo as doações para o grupo, para a irmã e para a professora. Enquanto o ganho dos seus colegas era saborear o wafer, o dela era ser vista como boazinha. Destacando que a reputação, mesmo no ambiente familiar (doar para parentes) pode ser um fator importante para desencadear o comportamento de partilha, além de poder desencadear uma recompensa pessoal como sugeriu Rilling et al. (2002).

Nem todas as crianças jogavam pelos seus parentes, como foi o caso de Joaquim, um menino seis anos e dois meses. Ele guardava os wafers para partilhar no seu aniversário, colocando na lancheira (brinde que se entrega aos convidados contendo doces). Quando perguntavam se não gostava de chocolates, ele dizia que sim, mas que sua lancheira de aniversário ficaria melhor se tivesse chocolate, seus amigos iriam gostar. Nesse caso, a satisfação pessoal estava presente, mas do que o fato de comer o wafer.

Será que esses atos têm motivação na reputação que ele teria com os amigos? O comportamento de Joaquim reflete os achados de Sell (1997), Nowak e Sigmund (1998) e Milinski et al. (2002), os quais afirmam que as pessoas cooperam com quem coopera. Ter um chocolate na lancheira faria dele um garoto de boa reputação. Será que os ganhos posteriores seriam maiores do que o prazer de comer seus wafers?

A reputação pode ser tão importante que, uma vez conquistada, pode ficar difícil ser destruída, especialmente se você constrói uma má reputação, como foi o caso de Suzana, uma criança com nove anos e onze meses de outro grupo investigado.

Em um grupo pequeno (abaixo de sete indivíduos), no quarto dia, Suzana nada colocou. As crianças o perceberam porque ela deixou à vista wafers que havia retido (não doado). Após a distribuição, ela ficou com mais do que os outros membros do grupo, em função do retorno privado (soma dos wafers doados pelas pesquisadoras mais os que ela havia guardado). Observando isso, Joana disse: "Nunca mais faça isso..." No dia seguinte, a turma toda fiscalizou fortemente Suzana. No dia da fiscalização intensa ela saiu do biombo sem wafers (ou, pelo menos, os havia escondido bem, dessa vez) e ficou apenas com o retorno que as pesquisadoras deram, no entanto, nesse dia, apareceu no grupo um trapaceiro. Teria Suzana repetido o ato? No momento em que foi feito o registro da doação longe das crianças, constatou-se que o envelope, no qual não havia doação, não era de Suzana e sim de Sheyla.

Percebeu-se, então, que, enquanto todos fiscalizavam Suzana, outra pessoa se aproveitara da situação. Infelizmente, isso não foi observado, no momento, pelas pesquisadoras, pois foi dada atenção demais a Suzana já que ela havia trapaceado e ganhado a reputação de trapaceira.

Talvez nos comportemos assim com indivíduos que consideremos trapaceiros. Mealey, Daood e Krage (1996) verificaram em adultos que as pessoas com fama de serem desleais ou criminosas são mais lembradas do que as benevolentes. Eles chegaram a essa conclusão, mostrando slides com fotos e dizeres sobre alguma característica dos indivíduos. Entre eles, havia alguns que tinham sido acusados de assassinato, roubado um colega da escola, praticado grandes roubos e outros deslizes similares. Dias depois, os participantes eram convidados a rever os slides sem os dizeres: as pessoas com características mais negativas foram mais lembradas pelos participantes.

Um mecanismo parecido pode ter funcionado nesse caso, tanto para as outras crianças do grupo como para as pesquisadoras, pois, até checarem os envelopes, acreditavam que Suzana havia repetido o feito.

Nos grupos pequenos, nos quais todos podem perceber mais facilmente nossas reações, trapacear pode estragar nossa reputação. Em alguns casos, o grupo não permite a trapaça. Quando estamos sendo vigiados, passamos a apresentar mais 
comportamentos de generosidade do que realmente temos (Zarbatany et al., 1985), ou podemos nos aproveitar da fama do outro, como fez Sheyla, que não doou nada no dia seguinte e um wafer apenas no último dia. Suzana ainda chegou a doar dois no quinto dia e depois voltou a se comportar como trapaceira, afinal, mais alguém no grupo se comportava como ela sem ganhar a fama. É possível que a punição não tenha sido alta o suficiente para inibir o comportamento de trapaça nos últimos dias de jogo. Porém, o aparecimento de outra trapaceira pode ter confundido o grupo, dificultando a vigilância.

A reputação só faz sentido em ser uma boa razão para se manter cooperando se todos sabem quem coopera e que o comportamento do benfeitor contribui para o ganho individual de outro, mas é uma boa explicação de porque cooperamos com um cooperador. Isso foi o que ficou evidente no caso de Manuel, um garoto de sete anos e um mês que sempre doou três wafers do primeiro ao oitavo dia, nos jogos dos bens públicos, e sempre ouvia o deboche dos colegas: "quem é o idiota que está doando três?"

O ganho de Manuel nos oitos dias de jogo foi de 2,9 wafers, enquanto que o do grupo foi em média 4,3. No último dia de jogo, ele foi o único doador do grupo. Como resultado, o grupo ganhou menos de um wafer de retorno $(0,3)$ e todas as crianças, exceto Manuel - o bonzinho ficou com menos de um $(0,3)$ já que teria doado todos -, ficaram com 3,3 (retorno privado).

No último dia, as pesquisadoras contavam a história dos bens públicos, informando que a maior parte daquilo que temos pertence a todos - nem todos contribuem com o mesmo valor, mas ganham em valores semelhantes, ou seja, nem todos doam a mesma quantidade de wafers, mas todos recebem o mesmo. Exemplificavam em linguagem simples e as crianças compreendiam que tinham perdido muito, pois se todos tivessem cooperado doando três, ganhariam 72 wafers.

No caso desse grupo, foi dito que só uma pessoa doou no último dia. Nesse momento, Manuel revelou para todos ser o doador máximo, então, um aluno levantou e doou, do seu montante, um wafer para Manuel. Logo em seguida, todos do grupo fizeram o mesmo. Naquele dia, o "bobo" foi o que mais ganhou chocolates $(12,3)$. Um ato digno de aplausos?

O comportamento dos alunos do grupo no último dia corrobora fortemente para que a reputação seja uma pressão para que cooperemos com os indivíduos que são bons, como sugeriu Sell (1997), Nowak e Sigmund (1998) e Milinski et al. (2002). E, nesse caso, o altruísmo recíproco direto se fez presente: as crianças retribuíram o favor, não com o mesmo valor, mas o "bobo" foi recompensado, mesmo assim ele não ganhou mais do que seus colegas ganharam ao longo dos oito dias. Mas questionamos: o que fez Manuel se manter cooperando? Certamente não foi a reputação, pois só foi percebido no último dia, mas poderia ser uma satisfação pessoal, em função de experiências anteriores, não fazer questão de comer os wafers ou até mesmo a incompreensão das regras, pois a reputação não basta se você é o único doador.

Manter-se cooperando em um grupo só vale a pena se existirem poucos trapaceiros, como sugerem trabalhos de Semmann, Krambeck e Milinski (2003) e Hauert, De Montes, Hofbauer e Sigmund (2002a; 2002b). Nesses grupos, perde-se menos sendo trapaceiros. $\mathrm{O}$ que pode parecer também injusto, como constatou João, um garoto de oito anos e 10 meses, que dizia: "Eu dei três e ganhei dois? Isso é injusto".

A frase de João reflete uma revolta comum no dia-a-dia. Por exemplo, pagamos impostos e nem sempre usufruímos o que merecemos pelo valor pago porque alguém deixou de pagar. No dia do comentário de João, após todos fazerem a doação e as pesquisadoras terem colocado dois wafers para cada um wafer que estava no envelope, distribuíram cinco wafers para cada criança (retorno).

A conta que João fez incluía seu investimento (três wafers) e seu lucro (dois wafers). No segundo dia de jogo, ele ficou com cinco chocolates, mas não achou justo, pois, no seu grupo, algumas crianças nada doaram (investimento zero) e ficaram com oito (lucraram cinco).

Nas outras sessões, continuou doando três no máximo e um no mínimo. O que o manteve como um cooperador, mesmo sabendo que seu retorno seria abaixo do esperado? João tanto poderia estar procurando essa aprovação, quanto poderia estar agindo como achava que era correto. Não obstante, informava aos outros o quanto havia doado, o que poderia lhe trazer ganhos secundários como acesso a determinados brinquedos ou privilégios em algumas brincadeiras.

As explicações para o altruísmo incluem que o ganho de um bom cooperador não necessariamente precisa ser retribuído conforme o que ele doa. Ele pode ter a retribuição com favores de outra natureza, o que é comum no dia-a-dia. João primava pela sua reputação que, em jogo com muitos jogadores, ficava diluída, os colegas não doavam tanto para João diretamente, pois o investimento era no grupo.

A insistência de João em se manter como doador pode ter sido influenciada pelo movimento do grupo, pois se manteve entre os que recebiam mais wafers. No primeiro dia de jogo, seu grupo obteve uma média de ganho de 7,1. O resultado de João esteve abaixo da média do grupo (ganhou 6,4), a mesma quantidade que mais da metade dos indivíduos do grupo. Os demais jogadores ganharam 7,4. Então, nesse grupo, todas as crianças ganharam 7,4 ou 6,4 wafers.

Ao longo das oito sessões, a média de ganhos foi de 4,8 para cada indivíduo do grupo. O ganho de João ainda ficou acima da média 5,1 (o maior ganho foi de 5,7 e o menor de $3,8)$. Isso porque ele se manteve cooperando, mas guardando alguns chocolates que, somados àqueles que os pesquisadores retornavam, deixavam sua média de ganho maior do que a dos grandes doadores. Nesse grupo, os indivíduos que chegavam a ganhar em média 3,8 mantinham uma cooperação alta (três ou dois wafers). Isso significa que, apesar da queixa sobre a injustiça dos ganhos, João estava controlando cuidadosamente suas doações. Assim, ao mesmo tempo em que se mantinha como um colaborador no grupo (doando um ou dois wafers), jamais arriscava reduzir demais seus ganhos como Manuel, que ganhou menos no grupo $(3,4)$, pois se comportou como cooperador máximo (três doações) em todas as sessões. João nos ensina que, em grupos grandes, ainda é bom manter-se doando, mas não arriscando tudo. Ele, de certa forma, fez uma avaliação baseada no que autores como Semmann et al. (2003) e Hauert et al. (2002a; 2002b) verificaram - é vantajoso cooperar desde 
que os outros cooperem.

Alguns indivíduos sabem avaliar essas condições melhor do que outros. E acredita-se que essa avaliação nem sempre é consciente no sentido de que os indivíduos calculam seus ganhos. No exemplo abaixo, ilustramos dois casos em que há um cálculo pensado pelos jogadores, no entanto, o que foi dito (calculado) foi diferente do que era feito. Os casos aconteceram em dois grupos diferentes: o de Marília, uma menina de oito anos e cinco meses e o de Pedro com nove anos completos.

Marília diz enfaticamente: "Gente, vamos doar três porque meu pai disse que se todos derem três, a gente ganha nove". Ela doou zero desde o primeiro dia apesar da recomendação. De forma semelhante, Pedro, com um ar meio malandro dizia sempre, antes de entrar no biombo: "Eu vou colocar três". Ele sempre colocou zero.

O que levou essas crianças a já iniciarem o jogo trapaceando e anunciando a boa reputação? Alguém falou para eles que os bons doadores recebem mais doações? Provavelmente não. Seria a reputação proposta por Nowak e Sigmund (1998), Krebs (2000) e Trivers (1971) que sugere que podemos trapacear fazendo com que os outros pensem que somos indivíduos que cooperam e, assim, recebermos os benefícios de pessoas benevolentes, pois temos habilidades para isso.

Tanto Marília quanto Pedro perceberam, de início, que trapacear é uma boa estratégia, desde que os outros não o percebam e não procedam da mesma forma. No primeiro dia, eles ganharam mais do que todos os outros. O ganho de Pedro no primeiro dia de jogo foi de 7,9 chocolates, enquanto que o grupo ganhou em média 5,8 (sendo o maior 6,9 e o menor 4,9). Marília ganhou no primeiro dia 7,1 wafers e a média do grupo foi de 6,2 - sendo 4,7 o menor ganho e 6,1 o mais próximo de Marília. O ganho de ambos foi visivelmente maior, mas quem percebeu? Provavelmente só os amigos mais íntimos, pois eles estavam em um grupo acima de 12 indivíduos.

Com o tempo, perceberam que, se os outros procedessem da mesma forma, eles perderiam. Provavelmente, por essa razão, Marília insistia: "Minha gente, coloquem três". No grupo de Marília, um dos jogadores ganhou o mesmo que ela no primeiro dia; portanto, ela não foi a única trapaceira do grupo. Talvez por essa razão tenha sido muito mais enfática que Pedro.

No grupo de Pedro, o ganho médio dos oito dias de jogo foi 3,6 (sendo o menor ganho 2,5 e o mais próximo de Pedro 4,2 ) e o de Pedro foi 4,7. Já Marília ganhou em média quatro chocolates, enquanto que o grupo, 3,4 (sendo o menor ganho três e o maior 3,7 ).

Esses dois trapaceiros foram, em média, os indivíduos que mais ganharam chocolates dentro dos seus grupos, maximizando seus ganhos à custa da cooperação dos outros. Outros apareceram ao longo do jogo, mas, para a felicidade de Pedro e Marília, eles só perceberam a vantagem dessa estratégia mais tarde. No entanto, os dois não perceberam que eles também perderam. Cada um poderia ter ganhado nove wafers por dia, pois, se todos doassem três, os pesquisadores adicionariam mais seis, entretanto, nem mesmo no primeiro dia eles tiveram esse ganho.

Porque somos controlados pelo ganho imediato e não pelo ganho potencial? É melhor ganhar o meio termo em vez de arriscar perder muito? Parks e Rumble (1994) e Cremer (1999) sugerem que a falta de confiança e a insegurança em relação ao comportamento dos outros membros do grupo tornam a trapaça sempre a melhor estratégia. Pedro e Marília refinaram essa estratégia ao tentar persuadir os outros de que estavam cooperando e, dessa forma, incentivaram a cooperação dos outros.

Em outra escola, Marcelo, de oito anos e três meses, percebe o mesmo que Marília e Pedro, mas sussurra em segredo no ouvido da pesquisadora: "Professora, eu vou doar zero". Olha depois para turma e grita: "Eu vou ser muito generoso". Colocando zero, o retorno dele é maior que os demais, como já comentamos. E os outros precisam saber que ele é generoso para que cooperem.

Cremer (1999) sugere que, se há confiança de que os membros do grupo cooperarão, a cooperação dos demais aumenta e, se Marcelo não doa, ele ganha mais, principalmente se todos acreditarem que o grupo é cooperador. A confiança reflete a reputação que Marcelo possui. Como não participávamos do jogo, nem exercíamos censura sobre quem não cooperava, apenas nós ficávamos sabendo da sua trapaça.

Não importa escolher entre o que pode ser ruim ou bom, se não há possibilidades de julgamento de sua escolha por parte de outrem. Isso ficou evidente em um grupo que foi eliminado da amostra total do trabalho de Alencar (2008) porque, sem que os pesquisadores tomassem conhecimento, a professora mandou as crianças doarem três wafers e explicou matematicamente que era mais vantajoso doar três. $\mathrm{O}$ grupo era composto por crianças de 5 a 5,5 anos e, como crianças obedientes, elas fizeram isso, todavia, criou-se um clima de muita tensão. Elas pareciam estar com medo, até que uma criança disse: "A professora disse que tínhamos que colocar três".

As pesquisadoras realizaram as sessões que restavam (mais cinco), pois já haviam combinado com as crianças que seriam oito encontros. E, na sessão seguinte, cientes de que não iriam utilizar aquele grupo no trabalho, instigaram as crianças perguntando: “quem vai saber quanto vocês doaram?” A pergunta revela que a reputação delas não seria abalada, fato que ficou confirmado, pois as crianças não doaram três nas sessões seguintes. Afinal, era um grupo grande. Quem saberia quem não doou três?

As crianças desse grupo simplesmente não seguiram as regras propostas pela professora, pelo menos, não no instante em que perceberam que o cumprimento das regras não poderia ser fiscalizado. Nesse momento, as mesmas pressões que modularam o comportamento dos outros grupos entraram em funcionamento aqui. É fácil e possível trapacear se não há vigilância.

Mas nem sempre trapacear deixa todos à vontade. No trabalho da Tragédia dos comuns, como todos os outros, as pesquisadoras não olhavam o que acontecia atrás do biombo. A tarefa desse jogo era relativamente simples, bastava checar a cor do crachá que iniciava o jogo com a do cartão entregue pelas pesquisadoras no momento da entrada no biombo: se coincidisse a cor, poderia pegar dois wafers, não coincidindo, não poderia pegar. Entretanto, houve uma vez em foi necessário olhar e intervir.

Nesse dia, Luciano de oito anos e meio pegou dois wafers na primeira vez em que foi ao biombo, embora a cor do seu crachá não indicasse que ele fora sorteado. Na segunda rodada, 
ele demorou bastante atrás do biombo e as outras crianças começaram a solicitar sua saída. Preocupada, a pesquisadora pediu para entrar no biombo para verificar se estava tudo bem. Notou que ele tremia com o cartão na mão, indicando que ele poderia pegar, pois havia a cor azul igual à do seu crachá. Agora, era hora de pegar os seus wafers, mas ele já os havia pegado. Ele olhou para a pesquisadora como se dissesse: "e agora"? Todas elas sabiam que ele tinha retirado seus dois itens indevidamente na rodada anterior, pois a cor do seu crachá não era compatível com a saída do biombo portando um wafer. A pesquisadora repetiu a regra e saiu do biombo. Ele pegou mais dois wafers.

Talvez Luciano não acreditasse que pudesse ser sorteado e já havia garantido seus wafers na primeira rodada. Quando constatou que poderia legitimamente ganhar, entrou em conflito. Os dois itens retirados indevidamente do bem comum afetaram a extinção do recurso nesse grupo (o recurso acabou no terceiro dia, neste dia em que Luciano pegou a mais). Provavelmente essa criança experimentou um sentimento muito comum e associado ao comportamento moral, a vergonha. Queremos destacar com esse exemplo que analisar a cooperação com base na seleção natural e na teoria dos jogos, por vezes, faz esses comportamentos parecerem desprendidos das emoções, aos olhos do observador desavisado, mas que, de fato, não o são como mencionado anteriormente. A Psicologia Evolucionista entende que tanto as emoções humanas quanto as suas habilidades cognitivas são adaptativas (Haidt, 2003; Pinker, 1999).

Esse dado do comportamento de Luciano teria passado despercebido se a pesquisadora não tivesse dado uma olhada por trás do biombo. O fato de a emoção ter sido evidenciada confirma que o comportamento de cooperação é modulado por alguns fatores ambientais e que a emoção tem um importante papel nas decisões morais (Haidt, 2001; 2003; Koenig, et al., 2007; Moll, Oliveira-Souza, Bramati, \& Grafman, 2002). Cooperar, em muitos casos pode não evidenciar o ganho, pois este pode estar refletido em recompensa pessoal, como sugeriu Rilling et al. (2002). Esses autores demonstraram que o cooperar está associado com a ativação de áreas cerebrais ligadas a processos de recompensa. Alguns dos atores descritos neste texto mantinham um prazer em cooperar, como Manuela, que não iria usufruir a recompensa que dávamos (os wafers). Além disso, sua forma de agir provavelmente a transformava, aos olhos dos outros, em alguém com comportamento de generosidade. $\mathrm{O}$ aumento da reputação também foi observado em outros casos (por exemplo: Marcelo, Marília e Pedro). Ao anunciar que era boa, a recompensa poderia aparecer de outras formas, além do ganho de uma maior quantidade de wafers. A idéia da reputação como causa próxima para desencadear o comportamento de cooperação nos outros, parece ter sido evidenciada nesses exemplos.

Com isso, verificamos que a reputação é um fator de importância para as crianças, muito embora nem sempre se comportem com generosidade. Entretanto, fazer com que os outros indivíduos percebam esta característica é importante, embora não se acredite que se revelar como bom não é uma atitude racionalmente calculada.

Esses relatos podem sugerir novas questões de investigação combinando os métodos da teoria dos jogos, com a entrevista sobre os motivos do comportamento para a compreensão do fenômeno, mantendo sigilo das doações entre os jogadores, mas não para os pesquisadores, que poderão fazer questões sobre os motivos das contribuições ou ausência delas.

\section{Referências}

Alcock, J. (1989). Animal behavior: an evolutionary approach. Sanderland: Sinauer.

Alencar, A. I. (2008). A cooperação em crianças da rede pública de Natal/RN uma abordagem evolucionista. Tese de Doutorado, Universidade Federal do Rio Grande do Norte, Natal.

Alencar, A. I., Siqueira, J. O., \& Yamamoto, M. E. (2008). Does group size matter? Cheating and cooperation in Brazilian school children. Human Evolution and Behavior, 29, 42-48.

Alencar, A. I., \& Yamamoto, M. E. (2008). A teoria dos jogos como metodologia de investigação científica para a cooperação na perspectiva da Psicologia Evolucionista. Psico, 39(4), 522-529.

Axelrod, R., \& Hamilton, W. D. (1981). The evolution of cooperation. Science, $21,1390-1396$

Benenson, J. F., Pascoe, J., \& Radmore, N. (2007). Children's altruistic behavior in the dictator game. Evolution and Human Behavior, 28, 168-175.

Brownell, C. A., Ramani, G. B., \& Zerwas, S. (2006). Becoming a social partner with peers: Cooperation and social understanding in one- and two-year-olds. Child Development, 77(4), 803-821.

Cremer, D. (1999). Trust and fear of exploitation in a public goods dilemma Current Psychology: Development, Learning, Personality Social, 18(2), 153-163.

Eisenberg, N., \& Mussen, P. H. (1995). The roots of prosocial behavior children ( $3^{\underline{a}}$ ed.). Cambridge: Cambridge University Press.

Fan, C. P. (2000) Teaching children cooperation - An application of experimental game theory. Journal of Economic Behavior \& Organization, 41, 1991-209.

Haidt, J. (2001). The emotional dog and its rational tail: a social intuition approach to Moral Judgment. Pychological Review, 108(4), 814-834.

Haidt, J. (2003). The moral emotion. In R. J. Davidson, K. R. Scherer \& H. H. Goldsmith (Orgs.), Handbook of affective sciences (pp. 852-870). Oxford: Oxford University Press.

Hauert, C., De Monte, S., Hofbauer, J., \& Sigmund, K.. (2002a). Replicator dynamics for optional public good games. Journal Theory of Biology, 218, 187-194.

Hauert, C., De Monte, S., Hofbauer, J., \& Sigmund, K. (2002b). Volunteering as Red Queen mechanism for cooperation in public games. Science, 296, 1129-1132.

Izar, P. (2009) Ambiente de Adaptação Evolutiva. In E. Otta, \& M. E. Yamamoto (Orgs.), Psicologia Evolucionista (pp. 22-32). Rio de Janeiro: GuanabaraKoogan.

Johnson, A. W., \& Earle, T. (2000). The evolution of human societies: from foraging group to agrarian state ( $2^{\underline{a}}$ ed.). Stanford: Stanford University Press.

Koenig, M., Young, L., Adolphs, R., Tranel, D., Cushman, F., Hauser, M., \& Damasio, A. (2007). Damage to the pre frontal increases utilitarian moral judgments. Nature, 446, 908-911.

Kohlberg, L. (1984). The Psychology of moral development. San Francisco: Harper and Row.

Krause, K., \& Harbaugh, W. T. (2000). Children's contributions in public good experiments: the development of altruistic end free-riding behaviors. Economic Inquiry, 38, 95-109.

Krebs, D. (2000). Evolutionary games and morality. In D. Katz (Org.), Evolutionary origins of morality: cross-disciplinary perspectives (pp. $313-$ 321). Londres: Imprint Academic.

Marinho, R. (2005). Prática na teoria: aplicações da teoria dos jogos e da 
evolução aos negócios. São Paulo: Editora Saraiva.

Markovits, H., Benenson, J. F., \& Kramer, D. L. (2003). Children and adolescents' internal models of food-sharing behavior include complex evaluation of contextual factors. Child Development, 74(6), 1697-1708.

Mealey, L., Daood, M., \& Krage, M. (1996). Enhanced memory for faces of cheaters. Ethology and Sociobiology, 17, 119-128.

Milinski, M., Semmann, D., \& Krambeck, H. (2002). Reputation helps solve the 'tragedy of the commons'. Nature, 415, 424-426.

Moll, J., Oliveira-Souza, R., Bramati, I. E., \& Grafman, J. (2002). Functional networks in emotional a nonmoral social judgments. NeuroImage, 16 , 696-703.

Nowak, M. A., \& Sigmund, K. (1998). Evolution of indirect reciprocity by image scoring. Nature, 393, 573-577.

Ohtsuki, H., Hauert, C., Lieberman, E., \& Nowak, M. A (2006). A simple rule for the evolution of cooperation on graphs and social networks. Nature, 441,502-505.

Parks, C. D., \& Rumble, A. C. (1994). Elements of reciprocity and social value orientation. Society for Personality and Social Psychology, 27, 1301-1309.

Piaget, J. (1994). Ojuizo moral da criança (4⿳亠丷a ed.). São Paulo: Summus Editorial. (Publicado originalmente em 1932)

Pinker, S. (1999). Words and rules. New York: Basic Books.

Rilling, J. K., Gutman, D. A., Zeh, T. R., Pagnoni, G., Berns, G. S., \& Kilts, C. D. (2002). A neural basis for social cooperation. Neuron, 35, 395-405.

Sell, J. (1997). Gender, strategies, and contribution to public goods. Social Psychology Quarterly, 60(3), 252-265.

Semmann, D., Krambeck, H. J., \& Milinski, M. (2003). Volunteering leads to rock-paper-scissors dynamics in a public goods game. Nature, 425, 390-393.

Suzuki, S., \& Akiyama, E. (2005). Reputation and the evolution of cooperation in sizable groups. Proceedings of the Royal Society, 272, 1373-1377.

Trivers, R. L. (1971). The evolution of reciprocal altruism. The quarterly review of Biology, 46, 35-57.

Zarbatany, L., Hartmann, D. P., \& Gelfand, D.M. (1985). Why does children's generosity increase with age: susceptibility to experimenter influence or altruism? Child Development, 56, 746-556.

Anuska Irene Alencar, doutora em Psicobiologia pela Universidade Federal do Rio Grande do Norte, é professora da Faculdade de Ciências, Cultura e Extensão do Rio Grande do Norte e Psicóloga da Secretaria Municipal de Saúde de Natal/RN. Endereço para correspondência: Universidade Federal do Rio Grande do Norte, Departamento de Fisiologia - Caixa Postal 1511, Lagoa Nova, Natal-RN. CEP.: 59072-970. E-mail: anuskaalencar@yahoo.com.br 